\title{
ERA-40 SST and Sea Ice Concentration Data
}

\author{
M. Fiorino
}

August, 27, 2001

Lawrence

Livermore

National

Laboratory 


\section{DISCLAIMER}

This document was prepared as an account of work sponsored by an agency of the United States Government. Neither the United States Government nor the University of California nor any of their employees, makes any warranty, express or implied, or assumes any legal liability or responsibility for the accuracy, completeness, or usefulness of any information, apparatus, product, or process disclosed, or represents that its use would not infringe privately owned rights. Reference herein to any specific commercial product, process, or service by trade name, trademark, manufacturer, or otherwise, does not necessarily constitute or imply its endorsement, recommendation, or favoring by the United States Government or the University of California. The views and opinions of authors expressed herein do not necessarily state or reflect those of the United States Government or the University of California, and shall not be used for advertising or product endorsement purposes.

This work was performed under the auspices of the U.S. Department of Energy by the University of California, Lawrence Livermore National Laboratory under Contract No. W-7405-Eng-48.

This report has been reproduced

directly from the best available copy.

Available to DOE and DOE contractors from the

Office of Scientific and Technical Information

P.O. Box 62, Oak Ridge, TN 37831

Prices available from (423) 576-8401

http://apollo.osti.gov/bridge/

Available to the public from the

National Technical Information Service

U.S. Department of Commerce

5285 Port Royal Rd.,

Springfield, VA 22161

http://www.ntis.gov/

OR

Lawrence Livermore National Laboratory

Technical Information Department's Digital Library

http://www.llnl.gov/tid/Library.html 


\title{
ERA-40 SST \& Sea Ice Concentration Data
}

\author{
Mike Fiorino \\ fiorino@llnl.gov \\ $+1-925-423-8505$ \\ Program for Model Diagnosis and Intercomparison \\ Lawrence Livermore National Laboratory \\ P.O. Box 808, L-264 \\ Livermore, CA 94551-0808 \\ USA
}

24 July, 200124 August, 2001

\begin{abstract}
The lower boundary condition of sea surface temperature (SST) and sea-ice concentration (sic) is a critical forcing of the lower frequencies in multi-decadal global atmospheric reanalyses such as ERA-40. Partly in response to the ERA-40 project, new SST/sic data sets have been developed that are considerably improved over those available to the firstgeneration reanalyses. This paper documents the input SST/sic data sets and the processing that created the daily SST/sic specification for the ERA-40 period 1956-2001.
\end{abstract}

The source data are: 1) the monthly mean HadISST data set from the UKMO Hadley Centre for 1956-1981; and 2) the weekly NCEP 2DVAR data for 1982-present. Both data sets are reanalyses of satellite and conventional SST/sic observations. The principal reason for the higher quality of these source data sets is the use of a common consensus sic and a common sic-SST relationship in the sea ice margins. The use of a common sic resulted in a very smooth transition between HadISST and NCEP 2DVAR, despite differences in data assimilation techniques and monthly versus weekly analyses. No special action was required to insure consistency at the transition unlike as was necessary for the AMIP II experiment (Fiorino, 1997).

The only special processing was application of the AMIP II mid-month calculation (Taylor et al., 2000) for the interpolation of monthly mean data to daily values. This scheme insures that the monthly mean of the daily-interpolated data is nearly identical to the input monthly mean.

Detailed comparisons of the SST and sic during the HadISST-NCEP transition, and other long time series, are given. We also compare the NCEP 2DVAR (circa 2000) to a newer version of the OISST (V2, circa 2001) and demonstrate that the small differences should have no impact on the ERA-40 atmosphere reanalyses. 


\section{Introduction}

Specification of the lower boundary conditions of sea surface temperature (SST) and seaice concentration for global atmospheric model/data assimilation systems has improved considerably since the first generation reanalyses of NCEP/NCAR, NASA DAO and ERA-15 in the early 1990's. The main data sources, then and now, are: 1) GISST from the UKMO Hadley Centre for monthly data before the era of satellite SST/sic observations (pre 1979/1981) (Rayner et al. 1996); and 2) the weekly OISST (Reynolds and Smith, 1994) of NCEP after 1981.

Special adjustments of these two SST/sic data sets were necessary for application to reanalysis and other global modeling experiments (e.g., AMIP I, Gates 1992), principally because of the treatment of sic in the SST analyses. ERA-15 required a sic mask (sic = 0,1 ) and Nomura (1998) painstakingly adjusted both the input sic data and the thresholds of sic to define ice versus open ocean appropriate to the ERA-15 global model.

For the AMIP II project http://www-pcmdi.llnl.gov/amip, Fiorino (1997) had to adjust the SST in the marginal sea ice margins during the transition from UKMO and to NCEP SST data because the differing SST-sic relationships lead to large $(>1.5 \mathrm{C})$ differences in the SST in the sic margin.

There were two basic causes: 1) each centre used a different sic data set; and 2) each centre took very different approaches to analyzing the SST in and near the ice margins.

To address these deficiencies, an international group of sic experts, under the coordination of Dr. Nick Rayner, UKMO, put together a common and "best" data set for use by both the UKMO and NCEP in the production of data sets for ERA-40.

Furthermore, both centres now explicitly account for sic during the SST analysis and use a common SST-sic relationship.

This paper gives a brief description of the source data sets and processing; and then evaluates the ERA-40 SST/sic during data set transition and compares the new NCEP OISST V2 to the NCEP 2DVAR used in ERA-40.

It should be acknowledged that the UKMO and NCEP made special efforts to produce the data sets for ERA-40. These centres in fact performed SST/sic reanalyses and thus represent the best input to atmospheric data assimilation. The ERA-40 project is extremely thankful for these special efforts.

\subsection{Overview of the Processing}

The basic objective of the data processing is to produce daily SST and sic in ECMWF GRIB. These steps are: 
1. interpolate monthly/weekly to daily values. For monthly mean data (HadISST), calculate mid-month values that the monthly mean of linearly-interpolated daily values is the same as the observed monthly mean. For weekly data (NCEP 2DVAR), assume the data are valid at the mid point of the week.

2. infill sic over land using the UKMO land/sea and $100 \%$ sic mask so that all points are defined

3. infill SST over land using appropriate land/sea mask and the NCEP "weave" successive scan scheme (used in NCEP 2DVAR/OISST).

4. convert to the ECMWF GRIB standard

Details are given in Appendix A.

\section{HadISST V1.1 and sic}

The Hadley centre sea Ice and Sea Surface Temperature (HadISST) data set is the successor to the GISST (Global sea Ice and SST see http://www.meto.gov.uk/research/hadleycentre/obsdata/GISST.html) data set series V1.03.1 (Parker et al. 1999).

The objective of HadISST is a "best" representation of lower frequency (climate) variability in the ocean whereas the NCEP operational analyses are more optimised for higher, synoptic-scale frequencies. It should be mentioned that the UKMO does perform a daily SST analysis for weather forecasting and uses the NCEP operational daily sic analysis.

There were two $1 . \mathrm{X}$ versions -- 1.0 and 1.1, and while officially the data set is 'V1' the final version used for ERA-40 was actually the second or 1.1. Essentially, 1.0 was a "beta" version that was adjusted after initial customer comments. Thus, we will refer to HadISST as HadISST V1.1 in this paper even though the official version is V1.

HadISST is a monthly mean analysis of SST and sic and is used only for the period 1956 - 1981 -- prior to the weekly NCEP 2DVAR reanalsed SST/sic. Intercomparison of HadISST and a monthly mean of the NCEP data during the overlap period 1982-1999 showed agreement sufficient to assure no large differences in basic features between the two SST/sic data. The NCEP data was favoured for the modern era (1982-present) because it contains higher resolution detail and is used operational for numerical weather prediction at many centres.

\subsection{Monthly $\rightarrow$ Daily Processing}

The traditional method of interpolating monthly data to daily values is to define the monthly mean as being valid at the exact middle of the month and then linearly interpolating. The problem with this approach is that the monthly mean of the daily values will not be the same as the original monthly mean. Thus, the interpolation smoothes in time and reduces the amplitude of the annual cycle. 
A new approach was developed by Taylor et al. (2000) that calculates the mid-month value so that the monthly mean is preserved under interpolation. This approach was. applied to the 1956-1999 HadISST data set and daily values produced for the 195601198111. However, the data were extended back to 1948 for future pre-ERA-40 period experimentation.

sic presents a special challenge in that mid-month values can be non-physical, i.e., $<0.0$ or $>100 \%$ to preserve the monthly mean. The daily interpolation process must reset the interpolated sic back to physical values when the interpolation goes out of bounds.

The implementation code for AMIP II was applied to HadISST at PCMDI. This code performs all processing to output daily values which were in turned converted to ECMWF GRIB.

\subsection{Consensus sic}

One of the more significant accomplishments of ERA-40 will be the coordination of sea ice observations and SST-sic relationships between the two main SST production centres of the UKMO and NCEP. While there are other centres making SST analyses for operational applications, most notably the U.S. Navy, both the UKMO and NCEP specialise in multi-decadal scales.

As discussed earlier, merging of previous UKMO and NCEP SST/sic data sets for AMIP resulted in huge discontinuities at the data set transition in Nov. 1981 of SST in the ice margins. By adopting a single sic data set for both centres, that AMIP II problem has been eliminated.

The consensus sic data was derived from a decision tree that selected "best" input data sets as a function of time and ocean.

These input data sets were:

1. weekly sic from the Navy/NOAA National Ice Center (1973-1994), available at NSIDC (http://nsidc.org/index.html)

2. daily sic from Nomura/Grumbine based SSMR and SSM/I (1979-1997), available at NCEP.

3. daily sic from NASA Goddard base on SSMR and SSM/I (197810-1996), available from NSIDC

4. daily sic from Bistol University based on SSM/I for the Antarctic (1987-present)

5. monthly sic from EMSR data, available from NSIDC

6. monthly sic from John Walsh in Arctic (1901-1995)

7. 10-day mean sic from Russian Arctic and Antarctic Research Program (AARI), 1953-1990 in the Russian Arctic, available from NSIDC

8. monthly ice-edge climatology from German and Russian charts in the Antarctic, available from Nick Rayner (1929-1962)

9. half-monthly sic for U.S. Great Lakes (1960-1979) 
Climatologies were used prior to the modern era (1979-present) for the Caspian Sea, Sea of Japan, Gulf of Saint Lawrence for years prior to 1979. These climatologies were constructed from modern-era observations or other data sets.

A common problem in passive microwave data sets is an underestimation of sic in the Arctic because of the formation of a thin layer of water ("ponding") during the summer. Active microwave measurements (scatterometers) are not sensitive to ponding and so these data were used to bias adjust (increase) the analysis to more realistic $90-100 \%$ sic. This correction is especially important for ERA-40 as the sea ice model does not account for ponding.

The decision tree was developed by leading sic experts and the resulting consensus data were averaged to monthly means for HadISST SST analysis and weekly for the NCEP SST 2DVAR. Further, the data sets were inter-calibrated to improve homogeneity prior to going through the decision tree.

\subsection{SST-sic relationship in the ice margins}

The UKMO and NCEP had very different approaches to analysing SST in the ice margins where there are few direct in situ observations (e.g., similar to ship observations in the eye of a tropical cyclone; the ship should not be there). NCEP, set the SST to -2 C at 85$90 \mathrm{~N}$ and the Antarctic continent and let the analysis scheme fill in the SST between these boundary zones and areas with SST observations. While this approach was not unreasonable from an observational perspective, the impact on atmosphere models is significant. Because one of the purpose of HadISST is to drive atmospheric climate models, a different approach was taken at the UKMO; namely, to develop a regressionbased relationship for SST and sic based on the limited observations in the ice margin and to then set the SST based on the sic observations.

NCEP tried a similar approach, but found different SST-sic relationships depending on how the regression was made and which observations were used. The SST-sic specification also impacted the SST analysis away from the ice margin. A consensus SST-sic relationship was adopted that both fit the observations and helped the fit of the SST analysis to the observations just outside the ice margin. Consequently, a very consistent transition from HadISST to 2DVAR was expected and achieved as will be demonstrated in Section 4.

\subsection{SST analysis}

The two main improvements in the HadISST SST analysis is the use of Reduced-Space Optimal Interpolation (Kaplan et al 1998) for reconstructing the global-scale, low frequencies in the ocean (e.g., ENSO) and improved data sources for adding localised detail. Among these data sources are an update to the Met. Office Historical SST (MOHSST7) and a better bias correction to Advanced Very High Resolution Radiometer (AVHRR) satellite SST anomalies. Further, the gravest temporal mode ("global warming") was removed prior to the RSOI and local detail added to yield a more realistic 
inter-month correlation. GISST V?.? had very low month-to-month persistence compared to other SST data sets (Hurrell and Trenberth, 1999)

\section{NCEP 2DVAR (V11) Reanalysed SST}

At the time the ERA-40 SST/sic data set was constructed (1999-2000), the best weekly NCEP SST analysis came from the new 2DVAR scheme (Reynolds et al. 2001). The main motivation for implementing a $2-\mathrm{D}$ variational vice the optimum interpolation (OI) analysis was computational; but a secondary consideration was greater generality and long experience with variational analysis (NCEP was the first centre to run a $3 \mathrm{DVAR}$ scheme for the atmosphere starting in 1992). The 2DVAR scheme also features a new bias correction of the satellite-derived SST observations and initial results showed that the combination of 2DVAR and bias correction produced better fits to in situ observations compared to the then-operational OISST (V1).

Beyond technical improvements in the data assimilation system, 2DVAR-analysed SST in the sic margin used the consensus SST-sic relationship developed jointly with the UKMO. It is this new feature that makes 2DVAR superior to OISST (V1) for atmospheric reanalysis vis-a-vis AMIP II (Fiorino 1997).

\subsection{Weekly -> Daily Processing}

The interpolation from weekly to daily values was done linearly without an attempt to ensure the weekly mean of the daily values returned the input mean. While the midmonth scheme could have been applied, it was found that the error was small and not able to recover lost information (this evaluation was done at PCMDI). Thus, slight smoothing was accepted, particularly as it would give a smoother forcing to the atmospheric model.

The only issue was when NCEP changed the mid point of the week in 1990. A simply blending of the two possible interpolations was made to insure smoothness.

\section{Evaluation of the ERA-40 SST/sic and comparison to AMIP II}

The ERA-40 plan called for using the monthly mean HadISST1.0 data for 1957 November, 1981 and the weekly NCEP 2dvar reanalysis data for December, 1981 present. As discussed earlier, the monthly HadISST data were interpolated to daily values using the AMIP II scheme.

The HadISST data used covered the period 1956-1998 and for NCEP 8 November, 1981 $\rightarrow 30$ December, 1998 (and up to the present time). Thus, we have a long period of 
overlap to intercompare and to check the transition between the data sets in December, 1981 (the recommendation was to start with the NCEP in the month proceeding the beginning time as the full month of November, 1981 was not available).

The monthly means from the daily-interpolated data, both NCEP and UKMO, were first checked technical soundness (every data point was read) and to concentrate on the lower frequencies. Then, sic "extent" was calculated as by Nomura (1997) for intercomparison with ERA-15 and found very similar magnitudes. Thus, the sic should have little or no impact on comparisons of ERA-15 and ERA-40.

The matching of sic is demonstrated in Fig. 4.1 where the Arctic sea ice extent for 197984 is shown using the shipping threshold of $15 \%$ and the meteorological threshold recommended by Nomura of 55\%. The differences are very small and on the order of $1 \%$ with no trend in the difference. Displays of the sic maps showed that most of the differences were in the sea ice margin or the area between complete ice and open ocean.

In Fig. 4.2 we show the fraction of ocean points in the sic margin (defined as sic $>=10 \%$ and $<=80 \%$ ) during the transition. No jumps are found although there is a suggestion of greater margin in the Antarctic after 1982, but this feature was also seen in the HadISST V1.1 data.

A more demanding consistency test is the SST in the sic margin. If both centres used the same relationship and the sic differences were small, then there would be little difference in the SST and no break in continuity. This mean is shown in Fig. 4.3 where we find slightly cooler water in the NCEP data poleward of the winter-time maximum. This cooling is a consequence of the small number of points in the region rather than a systematic difference. In AMIP II, the difference was on the order of $3 \mathrm{C}$.

Finally, Fig. 4.4 shows the anomaly of the zonally averaged SST over open ocean during the entire ERA-40 period. Again, no abrupt changes are found at the transition point in December 1981, but SST anomalies are greater before about 1978 near the ice margins in the HadISST data. This warming may be reflective of the change in sic and SST observations, most notably sic satellite observations starting in 1978. The large El Ninos of the 83,87 and 97 are clearly seen in the tropics and the warming of the northern Hemisphere mid-latitude oceans from around 1993 is an interesting feature in both the NCEP and HadISST data sets. We also general warming of the tropical oceans from 1956 - 2000 -- the so-called "global warming" signal.

The seemingly abrupt change in SST anomaly at the high Northern latitudes in the late 1970 was further analysed at PCMDI and at the UKMO by Dr. Rayner. Fig. 4.5 gives the \# of open ocean points and the mean SST in these points for both HadISST and NCEP at $67.5 \mathrm{~N}$. The number of points increases around 1980, but the temperature decreases. Dr. Rayner believes it may be related to how the AVHRR SST data is bias corrected in HadiSST since 1982 was when these data were first introduced into the UKMO analysis. 
Notice the higher amplitude of the annual cycle in the NCEP 2DVAR data. This feature is mostly explained by NCEP being a weekly (higher temporal variance) analysis, more liberal tolerances in the limits for the in situ observations and a different AVHRR bias correction.

The provisional conclusion is that the change is a "feature" of the data due primarily to changes in the observing system (e.g., no satellite $->$ satellite and different sic data sets)

In summary, the data sets show a great deal of consistency during the overlap period and while some variability due to changes in the observing system is present, the data should provide a much better boundary condition for ERA-40 and for seasonal forecasting.

\section{NCEP OISST (V2) Reanalysed SST}

As the production phase of ERA-40 began in 2000, NCEP continued to develop the 2DVAR scheme and after a detailed and rigorous evaluation concluded that an updated version of the OI scheme produced superior results as regard fits to observations. Thus, the operational weekly SST analysis is now OISST V2. The main deficiency in 2DVAR is the isotropic structure functions and bias correction of the satellite observations near the coast. While NCEP expects to correct these problems and implement a 2DVAR scheme at some point in the future, the current OISST V2 system is judges best, at least for now.

Although it might be desirable to change the ERA-40 SST to OISST V2 because it is "best," consistency requirements have a higher importance, so 2DVAR will be used. However, the obvious question is how much of an "error" will be made by using 2DVAR vice OISST V2.

Using the same software developed for 2DVAR, a parallel OISST V2 data set has been produced at ECMWF that is technical identical (the only difference is in file names) to the current 2DVAR data. A simple intercomparison shows potential error is very small and well below other error sources in the ERA-40 atmospheric reanalyses. The sic data were absolutely identical and in the following comparison we have masked out both land/glaciers and SST $<273.16 \mathrm{~K}(0 \mathrm{C})$ to focus on the analyses over open ocean.

In Fig. 5.1 we show the global average difference of the monthly means for the 19-year period. This difference is about $0.03 \mathrm{C}$, a number that is quite close to numerical precision of the daily GRIB data (0.01) itself.

We next look at the distribution of the global differences as a function of latitude in Fig. 5.2. The largest differences are in the near ice margins, especially Antarctic and OISST V2 is about $0.1 \mathrm{C}$ warmer. The rather abrupt change in 1991 may be related to the Mount Hudson (Chile) and Mount Pinatubo (Philippines) volcanic eruptions in 1991 ( see http://vulcan.wr.usgs.gov/Volcanoes/Chile/description hudson.html and 
http://vulcan.wr.usgs.gov/LivingWith/VolcanicFacts/volcanic impact.html). The bias correction is different and volcanic eruptions are a large source bias in the AVHRR SST observations.

The differences in bias correction and smoothing between the two analyses may also be seen in the anomaly from the annual cycle of the global mean SST as shown in Fig. 5.3. OISST V2 has slightly higher amplitude $(\sim 0.02 \mathrm{C})$, but the difference becomes extremely small after 1993.

Horizontal distribution of the difference is given in Fig. 5.4 for the 20 years. As found in the zonal averages, differences are greatest in the southern oceans, the Gulf Stream and Kuroshio currents and Barents and Nowegian Seas, reflective of slightly greater smoothing in 2DVAR. The pattern in the equatorial eastern Pacific is reflective of smaller $\mathrm{N}-\mathrm{S}$ gradients in the ENSO region. The magnitude of the difference variability is shown by the root-mean-square in Fig. 5.5. The variability is greatest in the same regions of large mean differences as expected, but the magnitude is about $0.5 \mathrm{C}$

While some mean differences seem rather large $(\sim 1 C)$, they actually represent slight shifts in the contours (less than $10 \mathrm{~km}$ ) and more variability at high wave number. This is demonstrated in the Gulf Stream (Fig. 5.6) and the equatorial Pacific (Fig. 5.7). In the case of the equatorial Pacific, note how the equatorial cold tongue extends further west in OISST V2 (colour contour) and has more waves (on a scale of several degrees of latitude) relative to the 2DVAR (black) contour. However, the high gradient zone between Hawaii and Baja California is virtually identical.

In conclusion, there are slight differences between OISST V2 and 2DVAR, with 2DVAR somewhat smoother. However, it seems highly unlikely that the ERA-40 atmospheric reanalysis would be respond to these SST differences in a detectable way. Thus, we judge the 2DVAR to be of equal quality for the purpose of multi-decadal reanalysis.

\section{Summary}

This report describes the ERA-40 lower boundary conditions of SST and sic taken for two modern reanalysed SST/sic data sets from the UKMO and NCEP. The monthly mean UKMO HadISST V1.1 data was used for the period 1958-1981 and the weekly NCEP 2DVAR data for 1982 to present.

The most significant feature the data set is the use of a consensus sic and SST-sic relationship in the UKMO and NCEP SST reanalyses. This feature resulted in a nearly seamless transition between the data sets. We also used a more correct scheme to interpolate the monthly mean data to daily values whereby the monthly mean of the daily interpolated data is preserved. 
Since the beginning of ERA-40 production, NCEP decided that an improved OISST (V2) produced better SST analyses vis-a-vis the 2DVAR scheme. We processed the new OISST in the same way as 2DVAR and have shown that the differences are small and should have no detectable impact on the quality of the ERA-40 atmospheric reanalyses.

\section{Acknowledgements}

I would like to acknowledge the tremendous work of Dr. Nick Rayner, UKMO and Ms. Diane Stokes, NCEP in preparing the sic data sets and for their very gracious assistance in accessing the data and processing for ERA-40.

\section{References}

Fiorino, 1997: AMIP II Sea Surface Temperature and Sea Ice Concentration Observations. PCMDI web report, http://wwwpcmdi.lln1.gov/amip/AMIP2EXPDSN/BCS OBS/amip2 bcs.htm

Gates, W. L., 1992: AMIP: The Atmospheric Model Intercomparison Project. Bull. Amer. Meteor. Soc., 73, 1962-1970.

Hurrell, J.W. and K.E. Trenberth, 1999: Global sea surface temperature analyses: multiple problems and their implications for climate analysis, modeling and reanalysis. Bull. Amer. Meteor. Soc., 80, 2661-2678.

Kaplan, A., Y. Kushnir, M.A. Cane and M. Benno Blumenthal, 1997: Reduced space optimal analysis for historical data sets: 136 year of Atlantic sea surface temperatures. $J$. Geophys. Res., 102, 27836-27860.

Nomura, A., 1998: Global sea ice concentration data set used in ERA. ECMWF ReAnalysis Project Report Series, no. 4, 25 pp., available from European Centre for Medium-range Weather Forecasts (http:/www.ecmwf.int)

Parker, D.E., N.A. Rayner, E.B. Horton and C.K. Folland, 1999: Development of the Hadley Centre sea ice and sea surface temperature data sets (HadISST), WMPO Workshop on Advances in Marine Climatology-CLIMAR99, pp. 194-203. [ Available from Environment Canada, Ontario].

Rayner, N.A., E.B. Horton, D.E. Parker, C.K. Folland and R.B. Hackett, 1996: Version 2.2 of the Global sea-ice and sea surface temperature data set., 1903-1994. CRTN 74, September 1996, Hadley Centre. 
Reynolds, R.W. and T.M. Smith, 1994: Improved global sea surface temperature analyses using optimum interpolation. J. Climate, 7, 929-948.

Reynolds, R.W., N.A. Rayner, T.M. Smith, D.C. Stokes, and W. Wang, 2001: An improved in situ and satellite SST analysis for climate. submitted to J. Climate, see ftp://ftp.ncep.noaa.gov/pub/cmb/People/reynolds/2dpap

Taylor, K.E., D. Williamson and F. Zwiers, 2000: The sea surface temperature and seaice concentration boundary conditions of AMIP II simulations. PCMDI report \#60, $20 \mathrm{pp}$. available at: http://www-pcmdi.llnl.gov/pcmdi/pubs/ab60.html

\title{
Appendix A. Data Processing
}

\author{
$\underline{\text { mkhadisst1.f }}$
}

\section{a. HADDIST1.1 -- Mid-Month SST and sic}

The observations were ftp'd from the UKMO and have since been deleted on that system

Data Location/Conventions

The root directory of the data is:

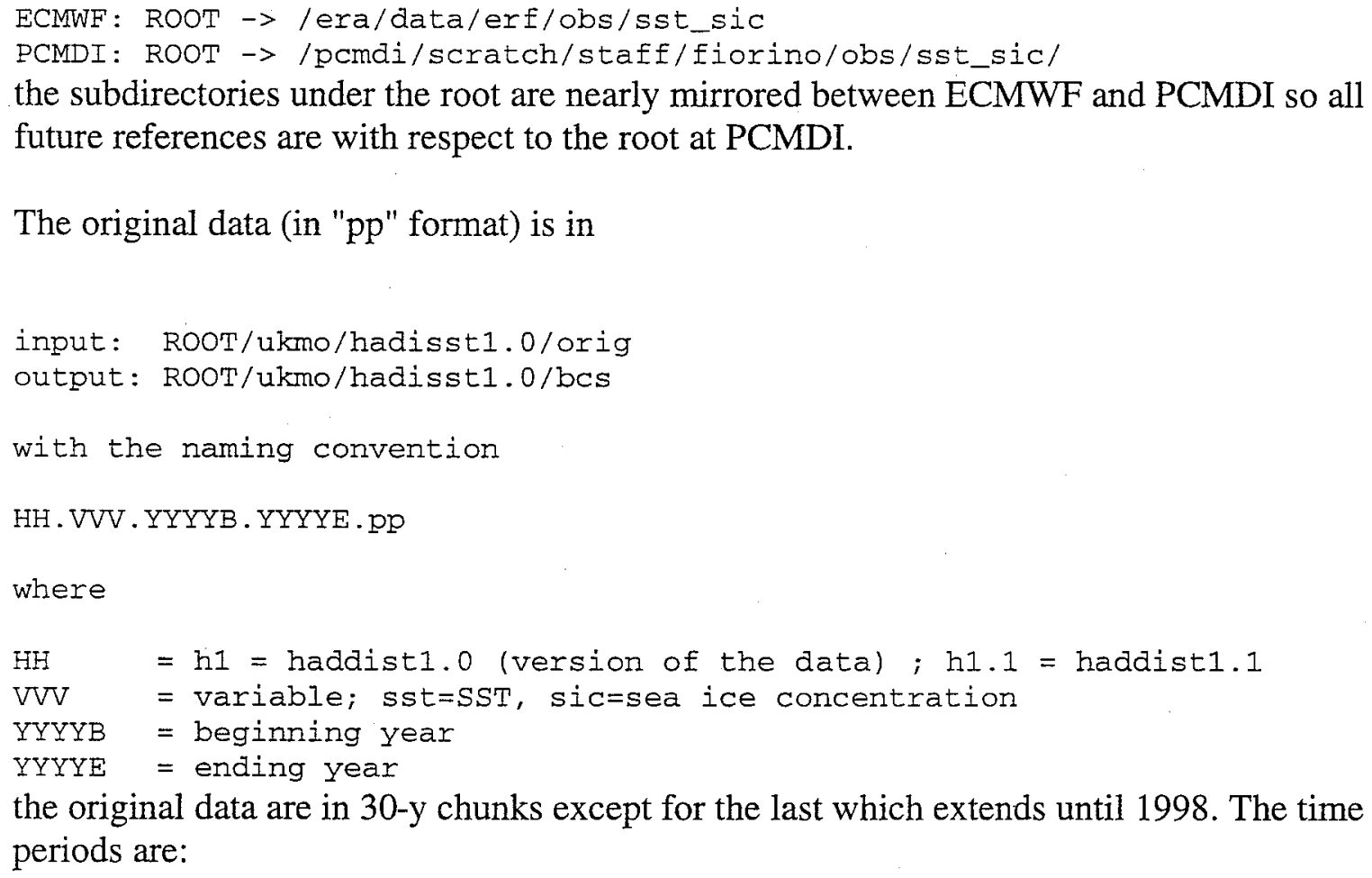


1901.1930

1931.1960

1961.1998

HADDIST1.0 -- Daily Interpolation

\section{Last Update: 2 August, 2001}

Send Comments to Mike Fiorino, PCMDI, LLNL

This work was performed under the auspices of the U.S. Department of Energy by the University of California, Lawrence Livermore National Laboratory under Contract No. W-7405-Eng-48. 


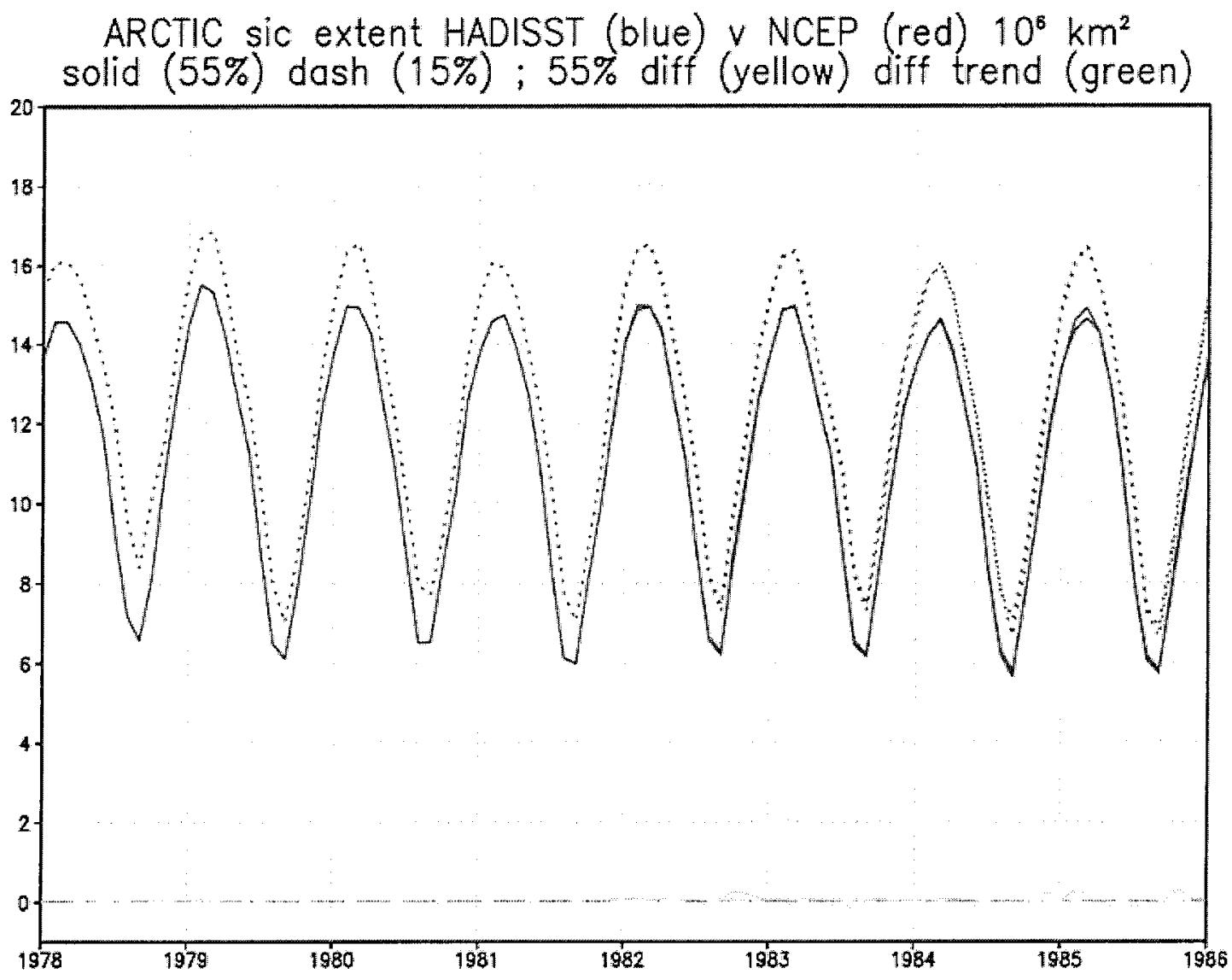

Fig. 41 
HADISST (197801-198111) \& NCEP (198112-198612) \% ocean in sic margin sic margin $=($ sic $>=10 \%$ \& sic $<=80 \%)$

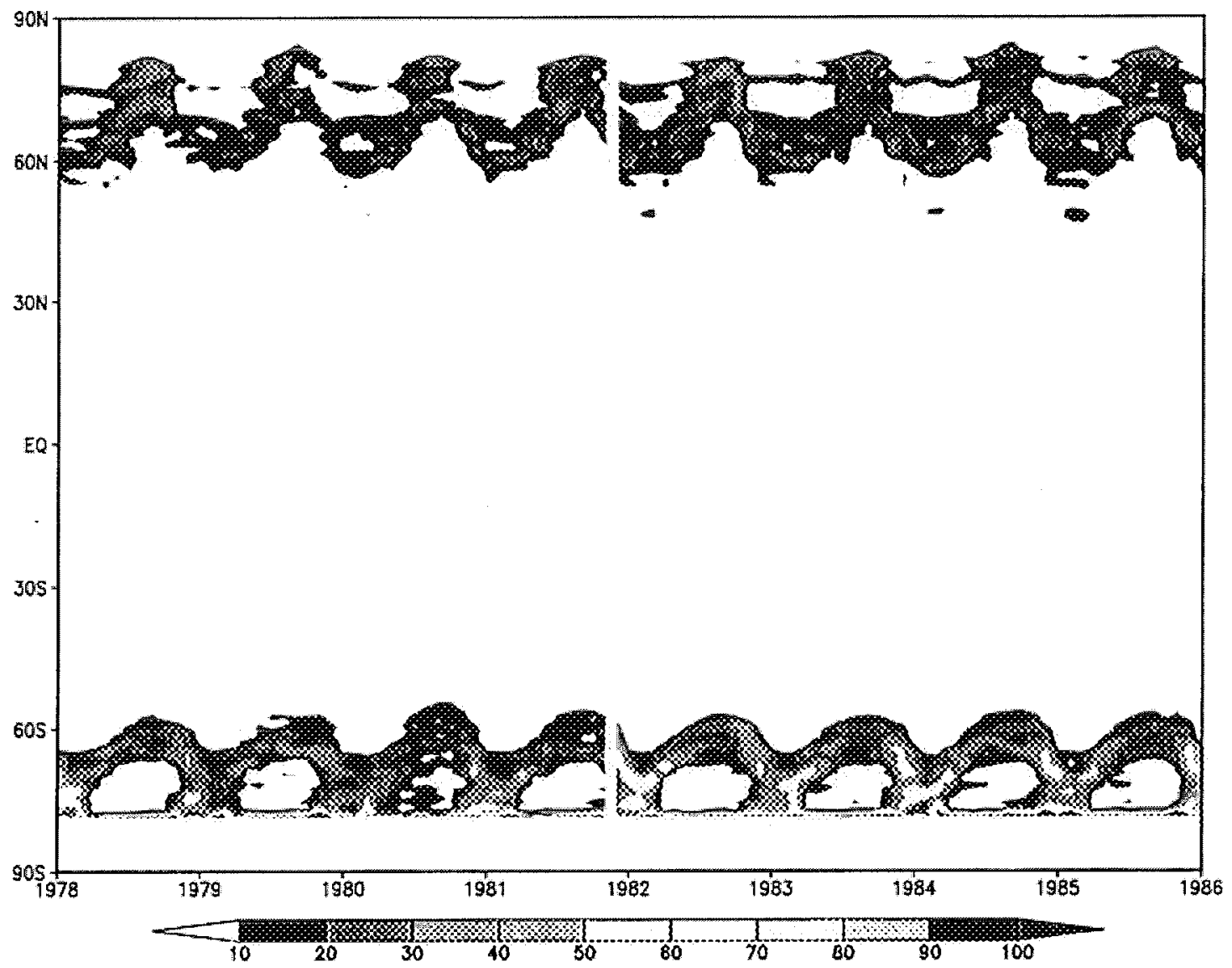

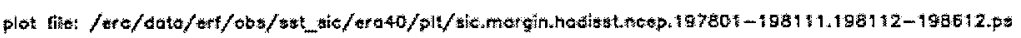

$$
\text { Fig } 4.2
$$




$$
\begin{array}{r}
\text { HADISST }(197801-198111) \& \text { NCEP }(198112-198612) \text { SST in sic margin }\left[{ }^{\circ} \mathrm{C}\right] \\
\text { sic margin }=(\text { sic }>=10 \% \text { sic }<=80 \%)
\end{array}
$$

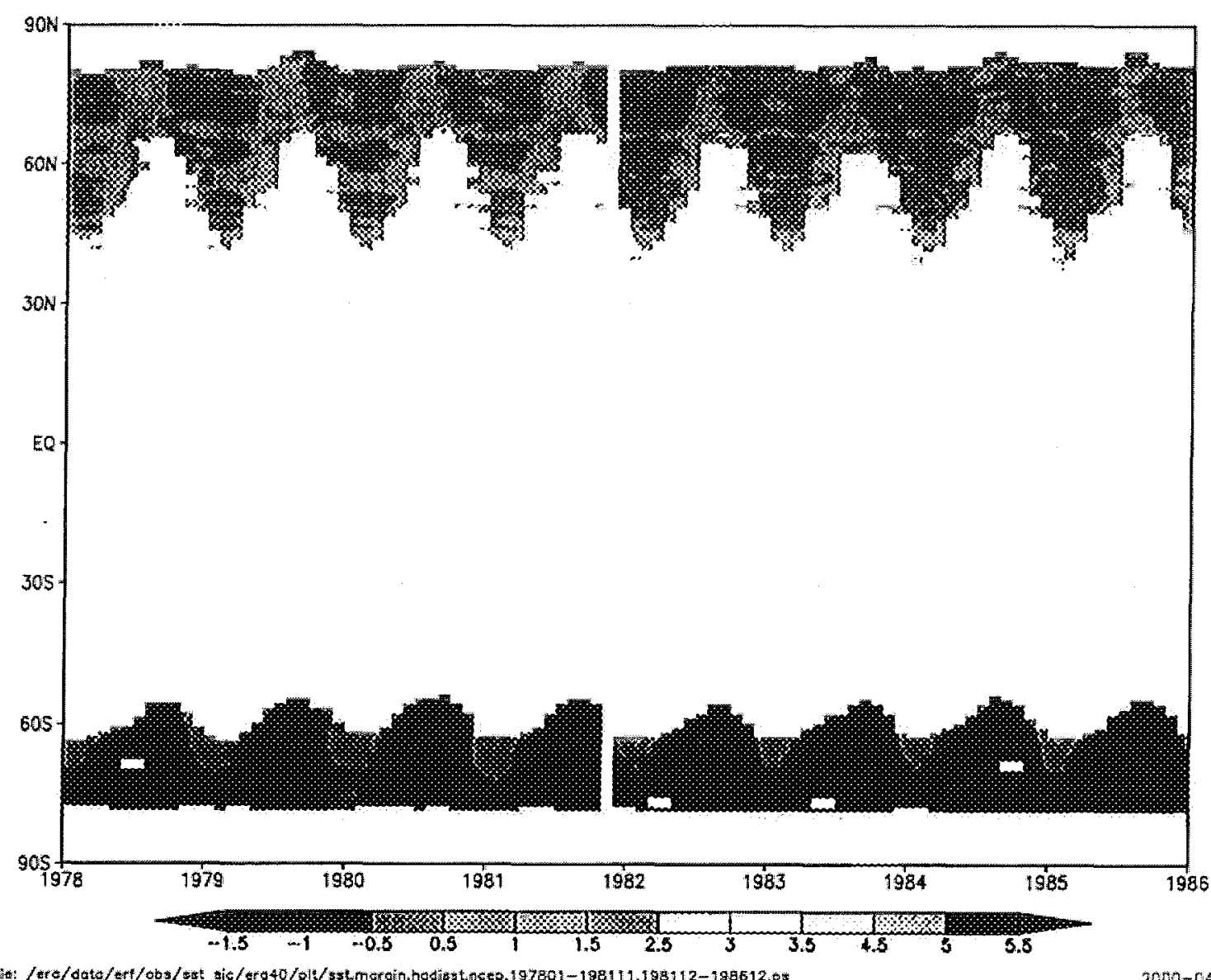

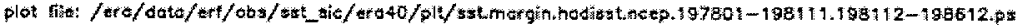

$$
\text { Fig } 4.3
$$


HADISST(195601-198111) \& NCEP(198112-199812) SST anom outside sic margin ['C]
remove 1982-98 annual cycle

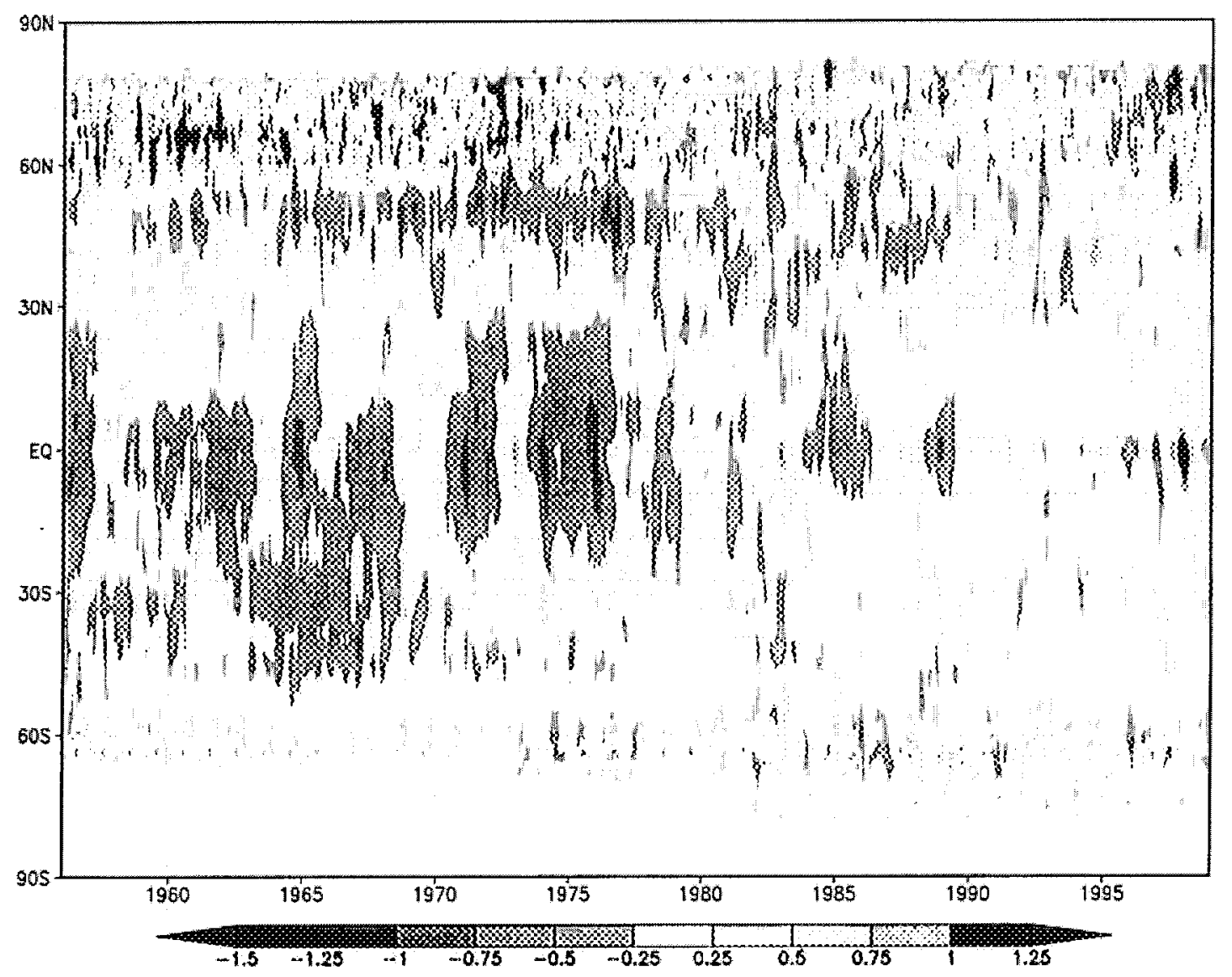

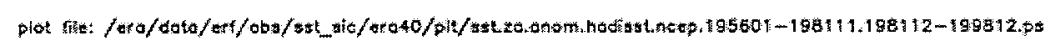


$67.5^{\circ} \mathrm{N}$ - - \# open sea SST points (bar) $\vee$ Mean SST (line with trend) bar: HadISST-yellow; NCEP-red line: HadISST-grean; NCEP-blue

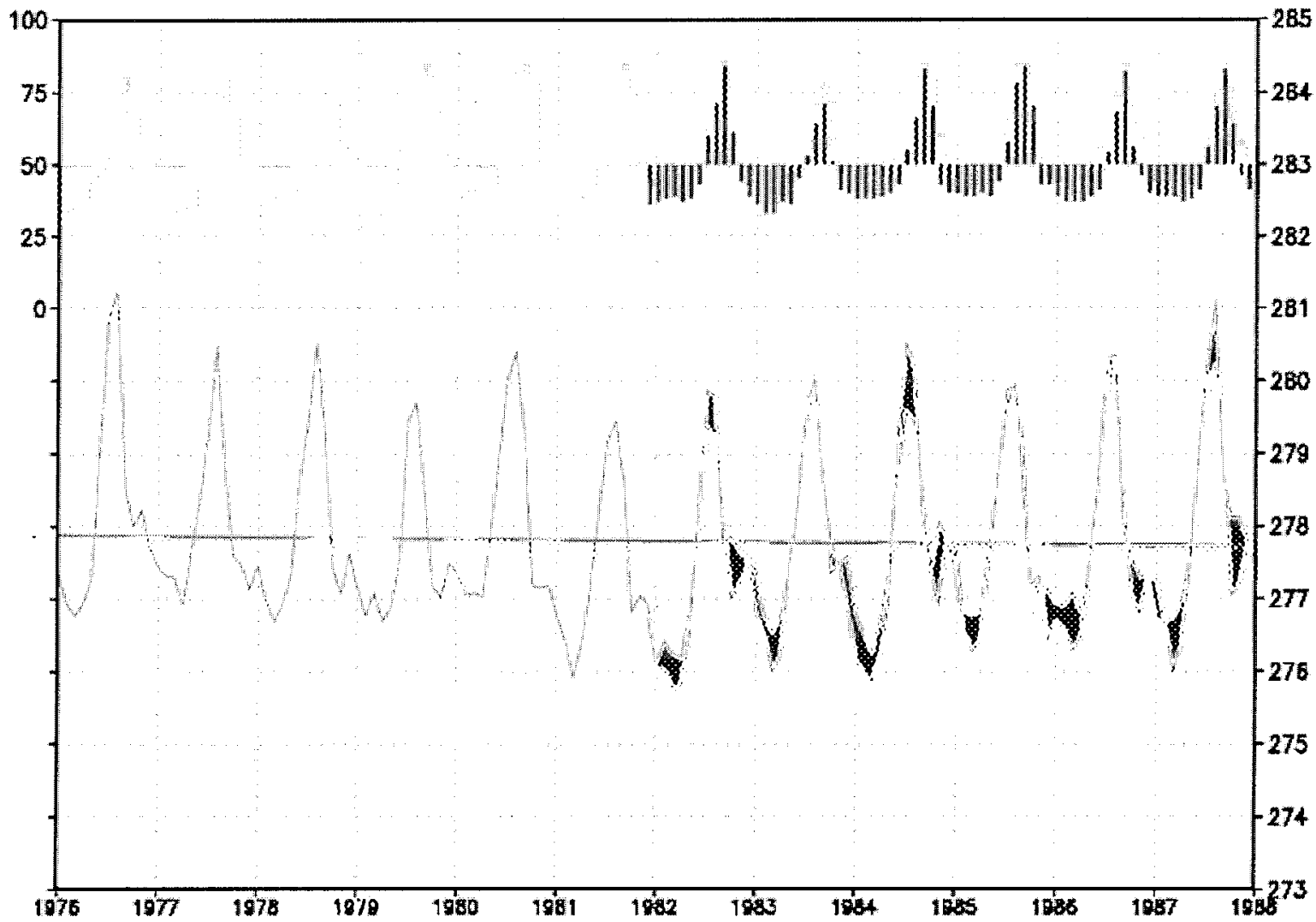




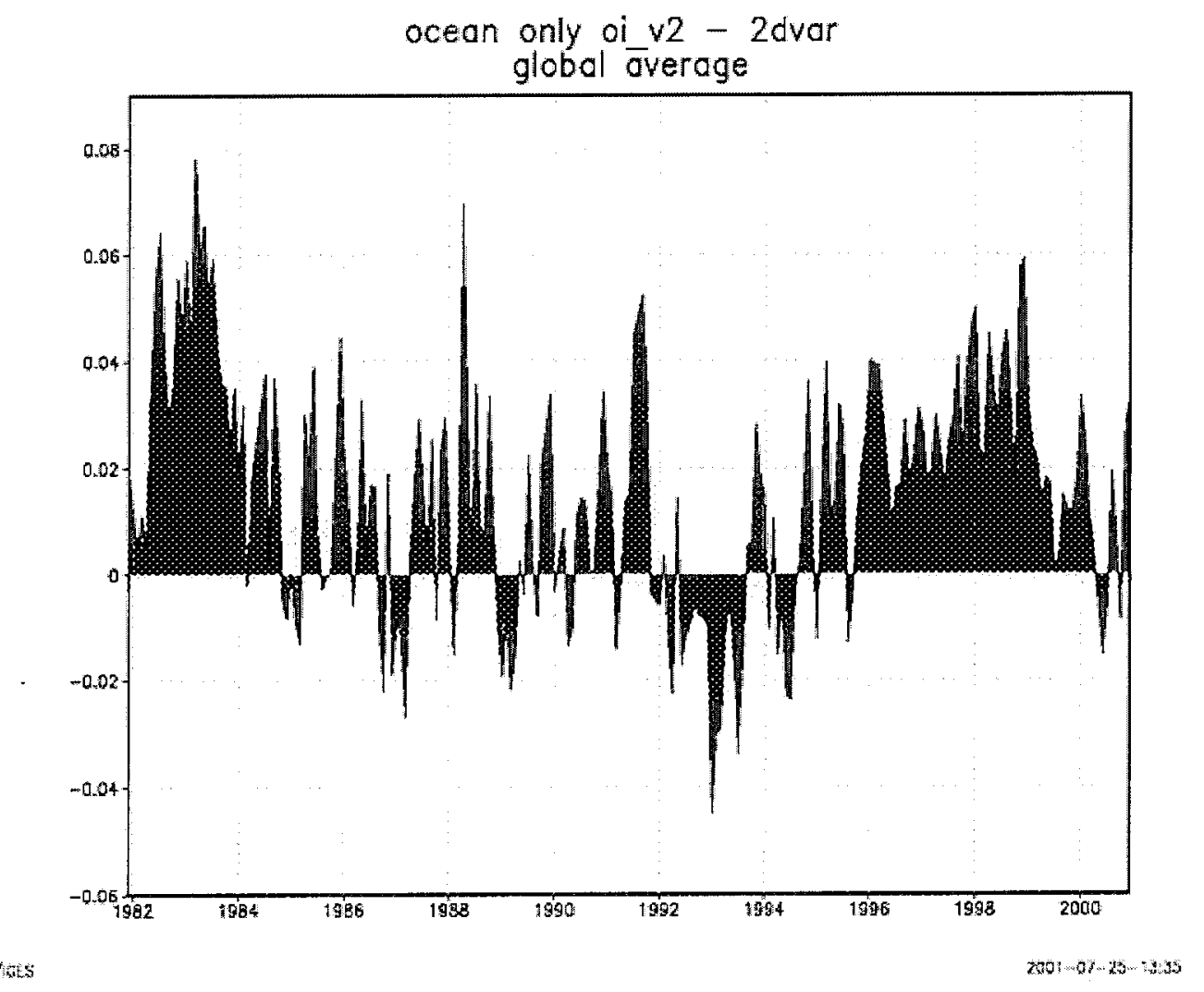

Fig 5.1 


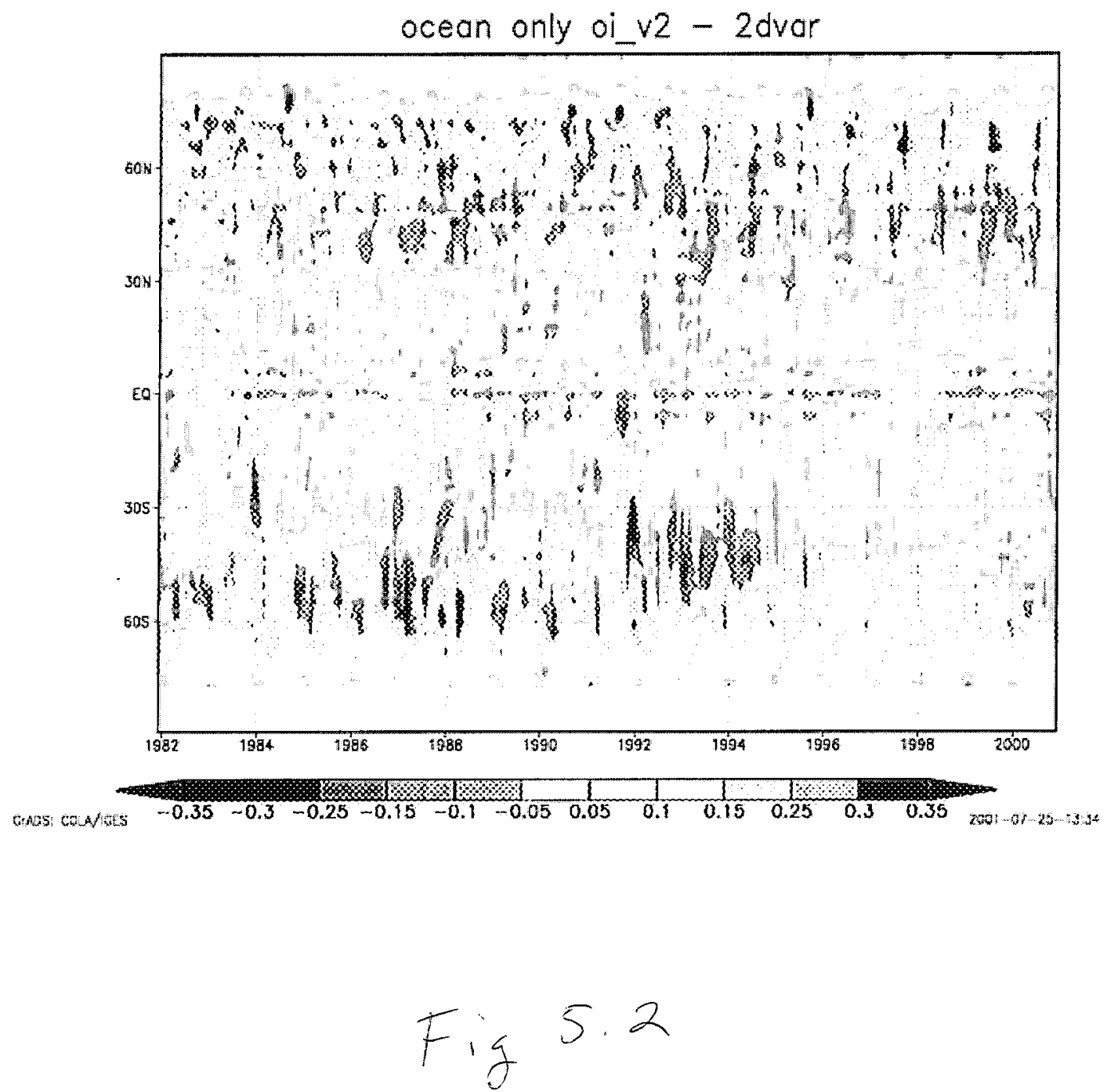


Friday, September 7, 2001

Page: 1

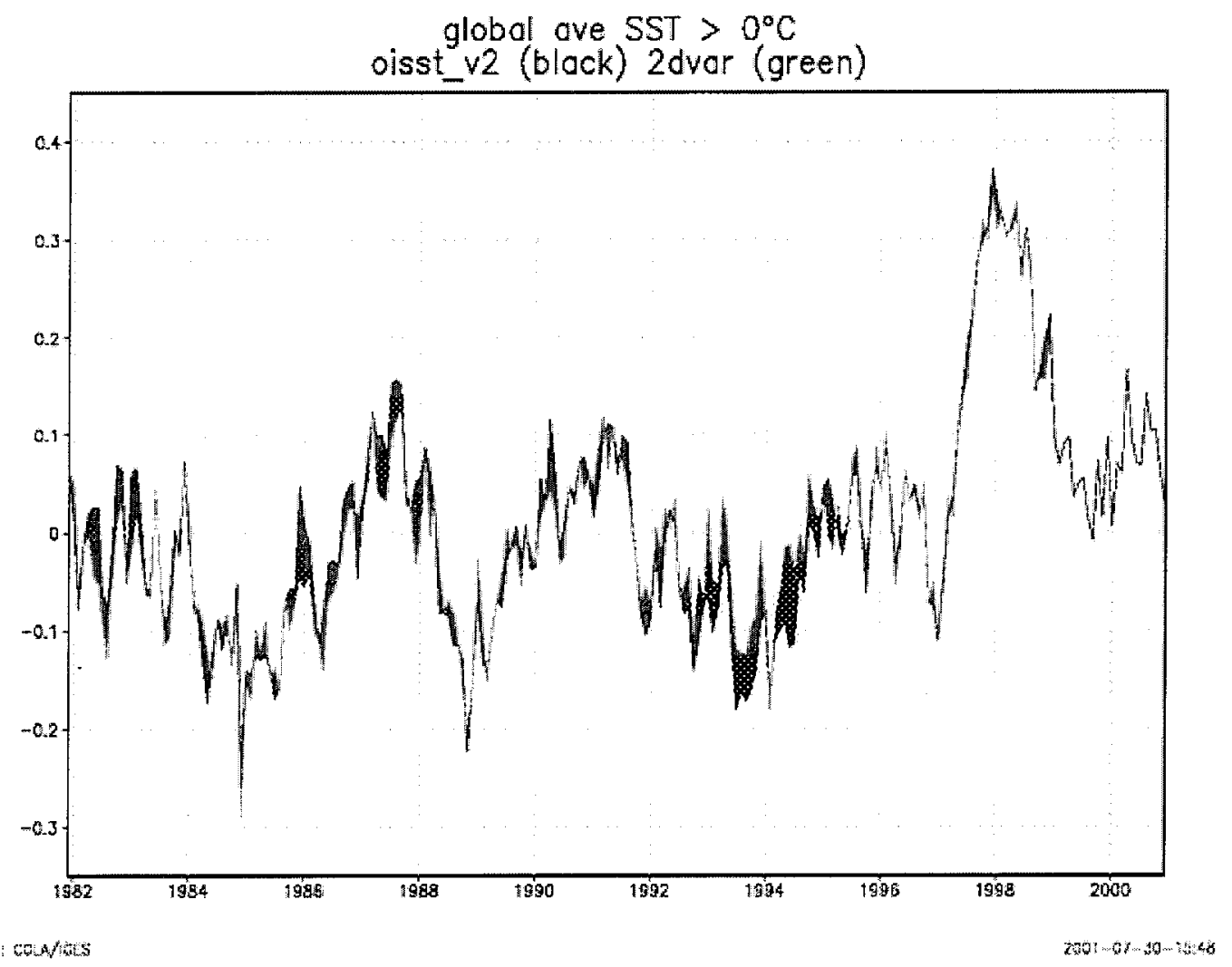

$$
\text { Fig } 5.3
$$

http://www-pemdi.linl.gov/fiorino/era40/sst_sic/ptt/oisstv2_v_2dvar/sst.oi_v2-2dvar.gavo.gt.o.gif 


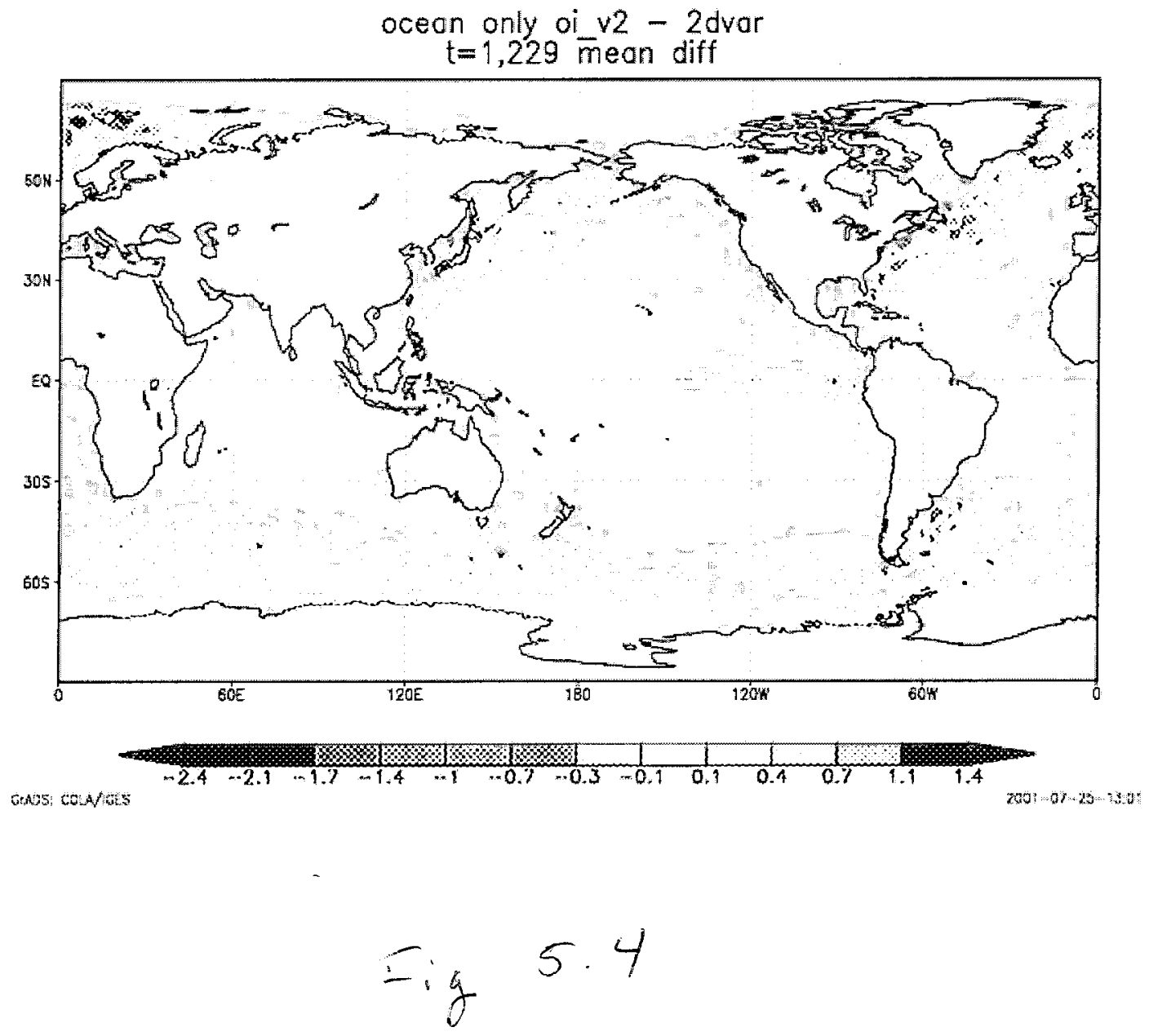




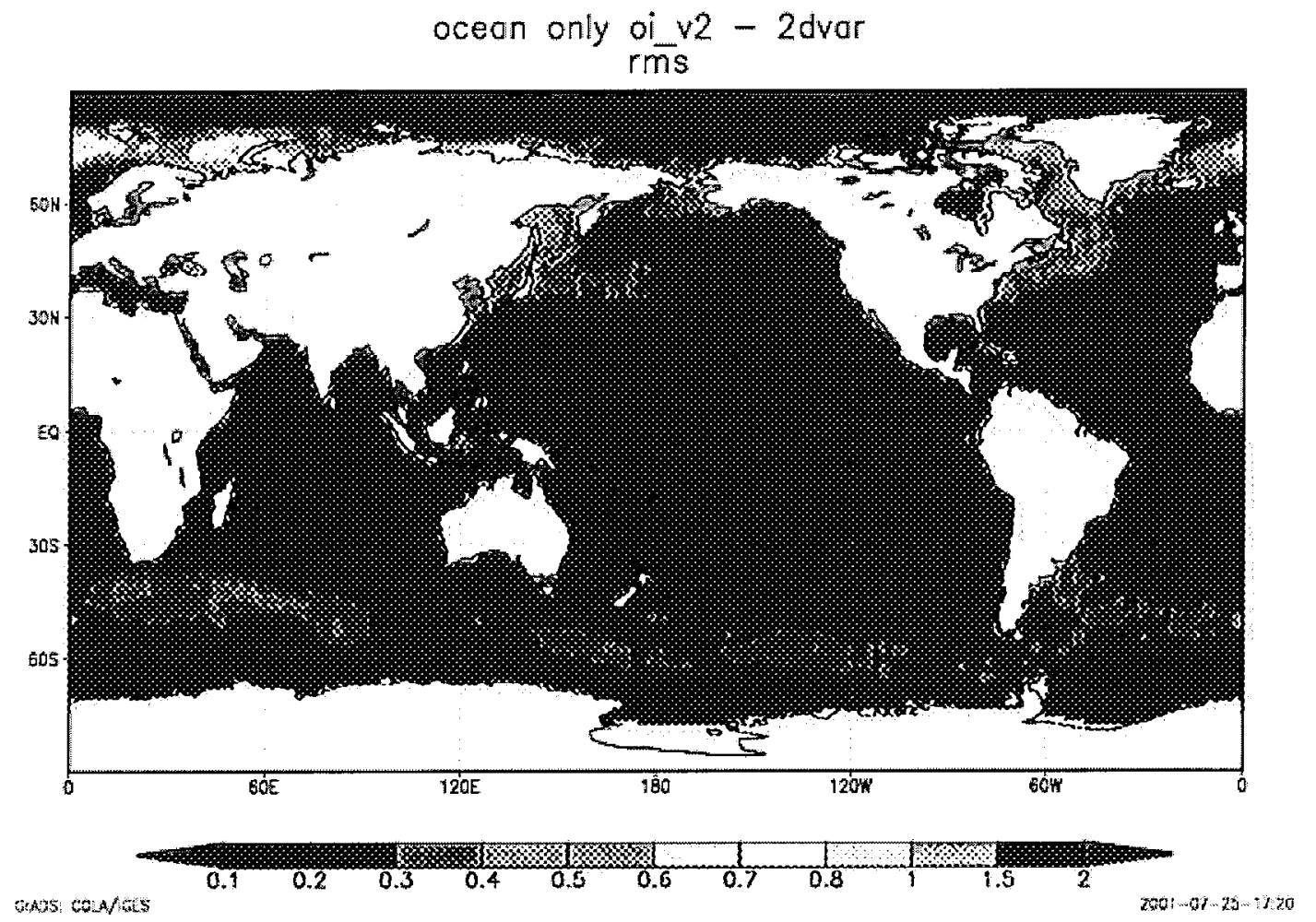

$$
\text { Fig } 5.5
$$


Friday, September 7, 2001

Page: 1

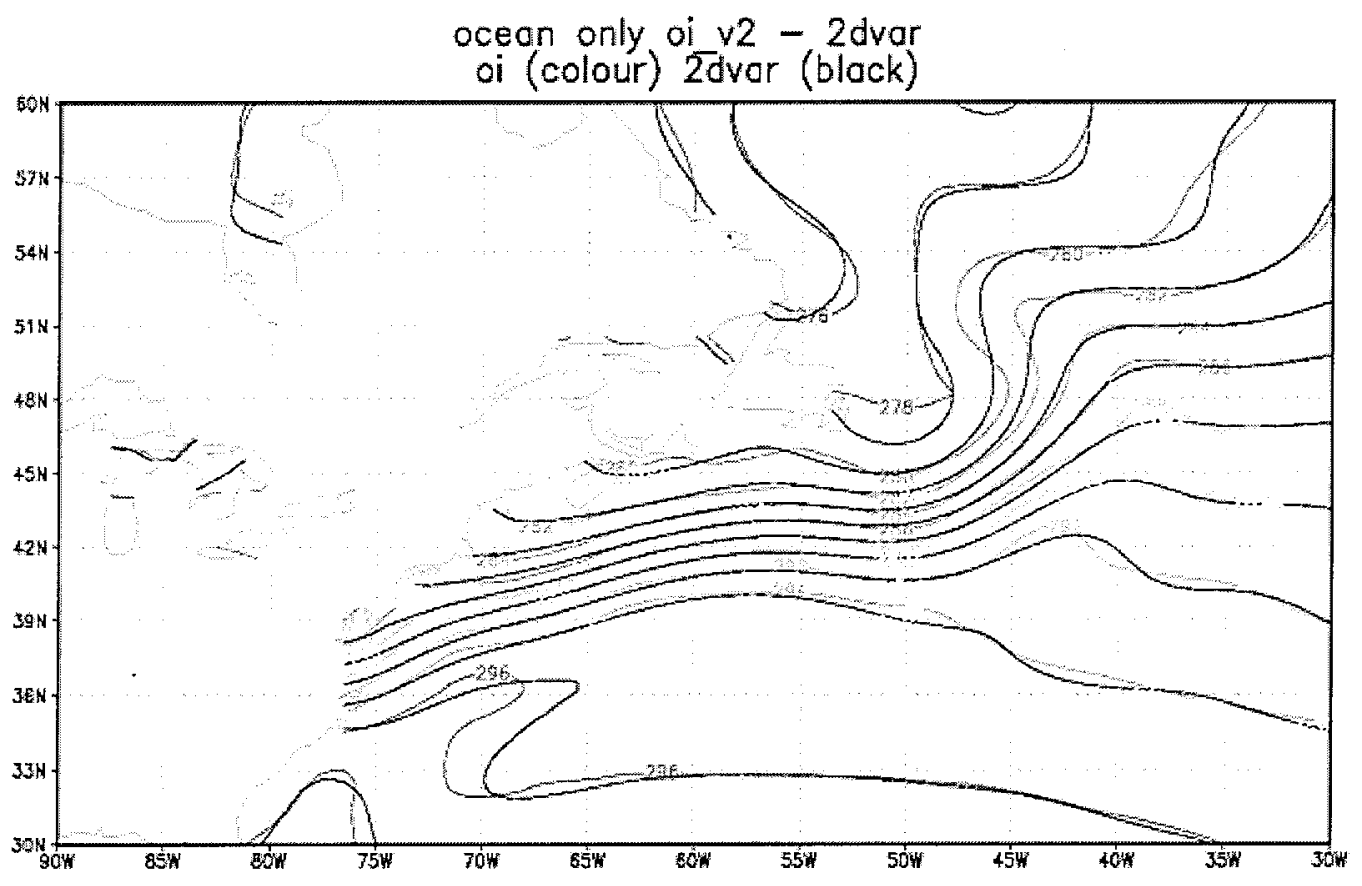

GAS: CON HOS

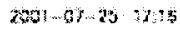

Fig 5.6

http://www-pemdi.linl.gov/fiorino/era40/sst_sic/plt/oisstv2_v_2dvar/sst.oi_v2-2dvar.mean.gulf.stream.gif 


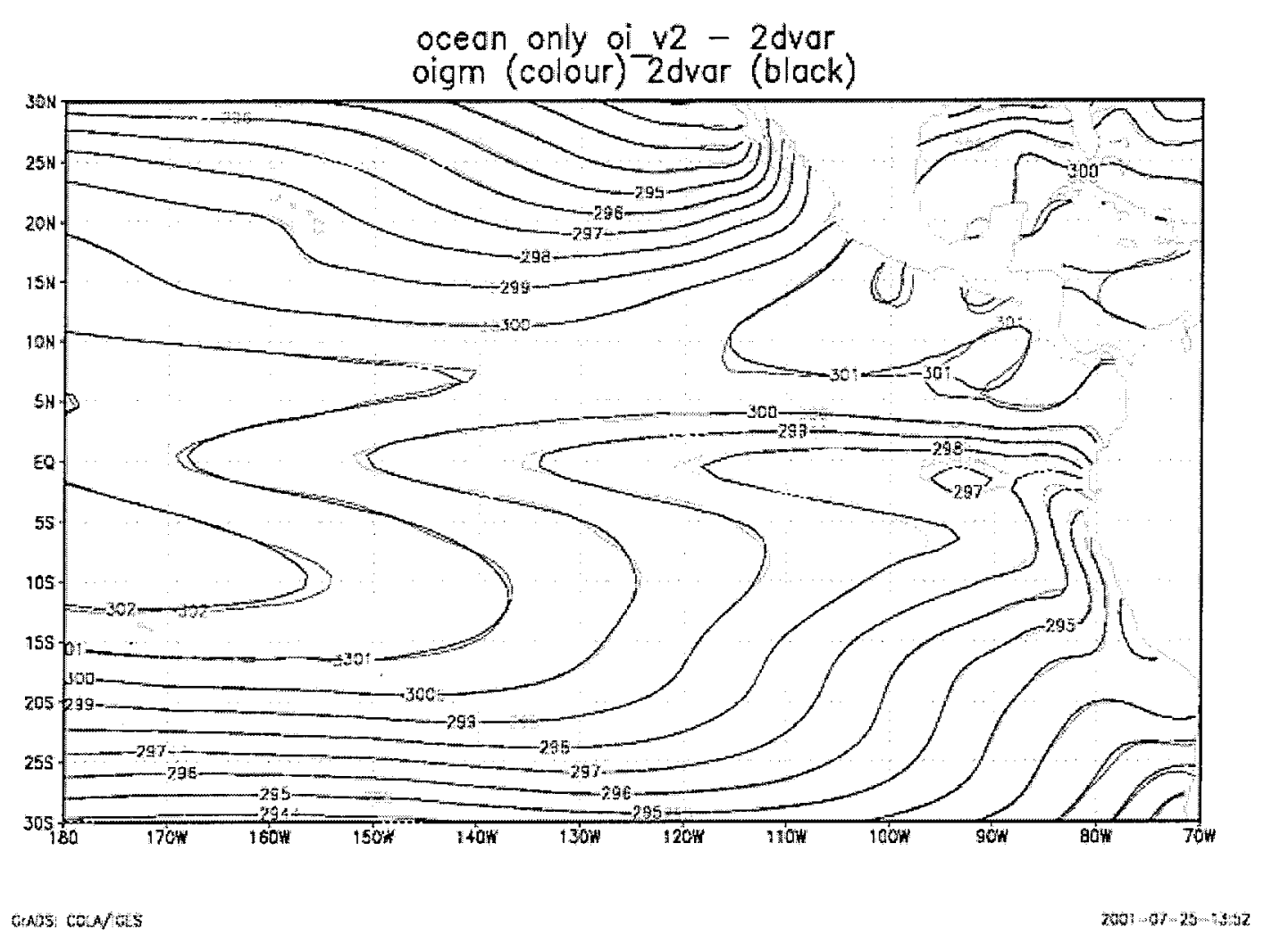

Fig 5.7 